\title{
Perceiving Racial/Ethnic Disadvantage and Its Consequences for Self-Esteem among Asian-Americans
}

\author{
Julie Spencer-Rodgers ${ }^{1,2}$ \& Kaiping Peng ${ }^{2}$ \\ ${ }^{1}$ Dept. of Psychology and Child Development, California Polytechnic State University, USA \\ ${ }^{2}$ Dept. of Psychology, Tsinghua University, USA \\ Correspondence: Dr. Julie Spencer-Rodgers, Dept. of Psychology and Child Development, California \\ Polytechnic State University, San Luis Obispo, CA, 93407-0387, USA. Tel: 1-805-756-2914. E-mail: \\ jsrodger@calpoly.edu
}

Received: April 16, 2014

Accepted: May 12, $2014 \quad$ Online Published: May 20, 2014

doi:10.5539/ijps.v6n2p117

URL: http://dx.doi.org/10.5539/ijps.v6n2p117

\begin{abstract}
This study is the first to test experimentally (vs. correlationally) whether perceiving racial/ethnic disadvantage leads to lower self-esteem among Asian-Americans. We manipulated perceived disadvantage by having Asian-American college students recall and write about experiences in which they were personally disadvantaged because of their race/ethnicity, and examined the effects of perceiving disadvantage on various outcome measures, including racial/ethnic identity, racial/ethnic salience (the number of ethnic identities participants listed on the Twenty Statements Test), and self-esteem. Consistent with experimental research with other racial/ethnic minority groups in the United States, the self-esteem of Asian-Americans was unharmed by recalling and describing past incidents of racially-based disadvantage.
\end{abstract}

Keywords: prejudice, race and ethnic discrimination, ethnic identity, self-esteem, Asians

\section{Introduction}

"I remember the first time I came to the United States ... I felt butterflies in my stomach...the immigration officer at the INS made some passes/jokes ... He was jeering at [my mom]. Then, another IO [immigration officer] came in and told him to leave us alone and just do what he was supposed to do with our documents. Then the newly arrived IO told me 'Welcome to America'." [Research participant]

Despite the rapid Asian population growth in North America in the past decades, the literature on perceived discrimination and stigma consciousness is limited for Asian-Americans, relative to other American racial/ethnic groups (Gee, Ro, Shariff-Marco, \& Chae, 2009; Hwang \& Goto, 2008; Lee \& Ahn, 2011; Son \& Shelton, 2011), and the effects of perceiving discrimination on self-esteem remain unclear. Numerous theories propose an "internalization hypothesis" and contend that stigmatized individuals inevitably internalize and/or are psychologically taxed by the prejudicial appraisals of others, leading to negative self-evaluations, psychological maladjustment, and poor physical health, e.g., Reflected Appraisal Theory (Mead, 1934), Rejection Sensitivity Theory (Downey \& Feldman, 1996; Mendoza-Denton, Downey, Purdie, Davis, \& Pietzak, 2002), Social Comparison Theory (Festinger, 1954), Social Identity Theory (Tajfel \& Turner, 1986), and the Perceived Unfairness Model (Jackson, Kubzansky, \& Wright, 2006). Other theories propose a "buffering hypothesis" and posit that racial/ethnic minorities effectively use self-protective strategies, such as racial/ethnic identification or external attributions, to protect and maintain self-esteem and wellbeing in the face of prejudice, e.g., Attributional Ambiguity Theory (Crocker \& Major, 1989), the Rejection-Identification Model (Branscombe, Schmitt, \& Harvey, 1999).

Most correlational studies conducted with Asian-Americans have found that perceptions of discrimination are related to lower self-esteem and psychological well-being (Chou, Asnaani, \& Hofmann, 2012; Gee et al., 2009; Gee, Spencer, Chen, Yip, \& Takeuchi, 2007; Lee, 2005; Lee \& Ahn, 2011; Noh, Beiser, Kaspar, Hou, \& Rummens, 1999; Noh \& Kaspar, 2003; Yip, Gee, \& Takeuchi, 2008; Yoo \& Lee, 2005), although a few show no association with self-esteem (Barry \& Grilo, 2003; Lee, 2003, Study 1; Mak \& Nesdale, 2001). These contradictory findings point to the complexity of the relationship between perceptions of discrimination, self-esteem, and psychological adjustment for Asian-Americans (for reviews, see Gee et al., 2009; Lee \& Ahn, 
2011). Moreover, all of the past research is limited by its correlational design, and experimental studies are needed to determine whether there is a causal link between perceiving discrimination and low self-esteem among Asian-Americans. The underlying assumption in correlational studies is that perceiving discrimination leads to a negative self-concept (perceived discrimination $\rightarrow$ self-esteem). However, correlation does not imply causation (Fisher, 1966), and it is equally plausible that people who possess low self-esteem are more likely to report that their racial/ethnic group is a target of discrimination (self-esteem $\rightarrow$ perceived discrimination).

Only one experimental study has tested whether perceiving discrimination leads to negative emotions among Asian-Americans. In this seminal study, Yoo and Lee (2009) found that Asian-American college students who imagined they had experienced multiple instances of discrimination reported greater negative affect than those who imagined they had experienced a single incident. Asian-Americans who were high in racial/ethnic identity were especially likely to be harmed by perceiving discrimination. Yoo and Lee (2009) noted that a limitation of their study was that participants only imagined they had experienced discrimination after reading a standardized vignette (e.g., being denied admission to a night club) and approximately one-third of participants reported "they could not relate to their vignette at all" (p. 76).

In this brief report, we present the results of the first study to test experimentally whether perceiving racial/ethnic disadvantage leads to lower self-esteem among Asian-Americans. We sought to expand the literature on this topic by using a manipulation with greater ecological validity (i.e., by having participants write about actual experiences with racially-based disadvantage) and by focusing on self-esteem as the dependent measure, a variable that has long been of interest to psychologists and social stigma researchers (e.g., Crocker \& Major, 1989; Lee, 2005; Mead, 1934; Noh et al., 1999; Tajfel \& Turner, 1986). The statistical models that we tested are presented in Figure 1. First, based on our experimental data, we tested the main effects of perceiving disadvantage on self-esteem (Model 1, path a), as well as on racial/ethnic identity and salience (Model 2, path b). Second, based on correlational analyses, we investigated whether racial/ethnic identity moderated the relationship between perceived disadvantage and self-esteem (Model 3, path c). The participants' open-ended accounts of racially-based disadvantage were coded by type of experience, and we report their frequency and median age of occurrence.

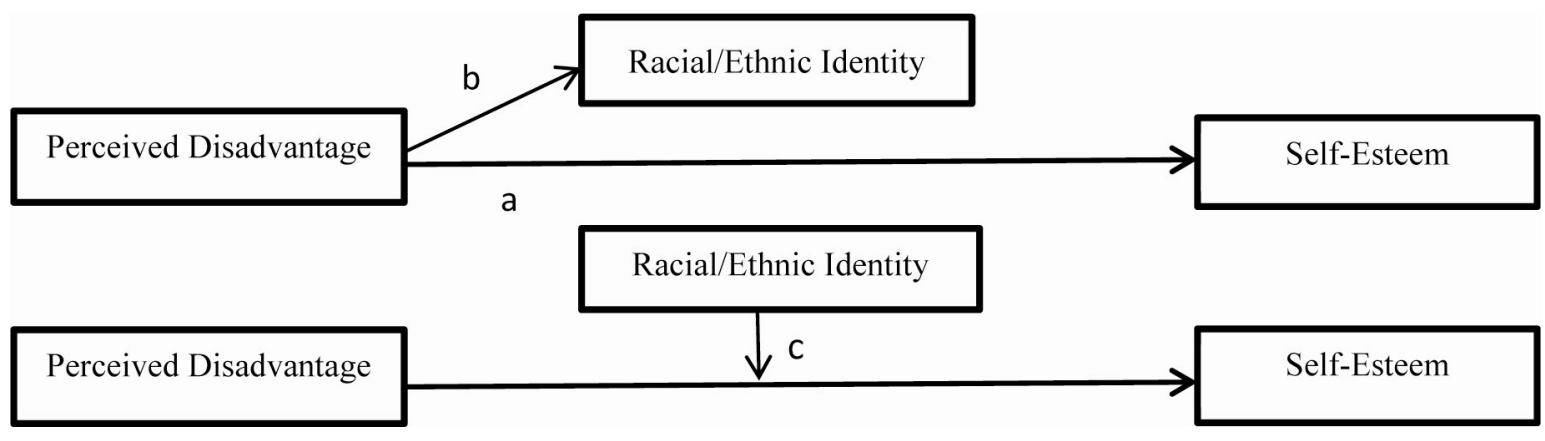

Figure 1. Statistical models tested in the current study

Model 1: path a, main effect of perceived disadvantage on self-esteem; Model 2: path b, main effect of perceived disadvantage on racial/ethnic identity (and salience); Model 3: path c, moderating effect of racial/ethnic identity.

\subsection{Experimental Effects of Perceiving Racial/Ethnic Disadvantage}

Experimental studies with other American racial/ethnic groups, such as African-Americans and Latinos, often have found that perceptions of discrimination are not linked to lower self-esteem, especially among individuals who make external attributions to discrimination (i.e., who attribute negative feedback to the prejudicial attitudes of their evaluator, rather than to personal failings) or who reject status-legitimizing ideologies, such as the belief in individual mobility and the Protestant work ethic (Crocker, Major, \& Steele, 1998; Major, Kaiser, \& McCoy, 2003; Major \& O'Brien, 2005). Given the mixed evidence in the literature with Asian-Americans described above, however, we did not offer a prediction regarding the main effect of perceiving racially-based disadvantage on self-esteem (Model 1, path a in Fig. 1).

Group identification (in this case, racial/ethnic identification) is another variable of importance to the link between perceived discrimination and self-esteem (Branscombe et al., 1999; Kaiser \& Wilkins, 2010; Operario 
\& Fiske, 2001; Tajfel \& Turner, 1986). When faced with widespread societal discrimination, minorities may counter that threat by identifying more strongly with the stigmatized group. As depicted in Figure 1 (Model 2, path b), we tested the main effects of perceiving disadvantage on racial/ethnic identity (i.e., how strongly attached one is to one's racial/ethnic group; Spencer-Rodgers \& Collins, 2006), as well as racial/ethnic salience (i.e., the centrality of race/ethnicity to the self-concept; McGuire, McGuire, Child, \& Fujioka, 1978). With respect to racial/ethnic salience, we were interested in whether perceiving disadvantage influences both the salience of specific ethnic identities (e.g., Chinese) and the salience of the broader pan-ethnic category Asian. To accomplish this, we administered an open-ended measure of the self-concept, the Twenty Statements Test (TST; Kuhn \& McPartland, 1954), and computed the proportion of ethnic and pan-ethnic identities participants listed on the TST. We hypothesized that priming perceptions of racially-based disadvantage would increase the psychological salience of ethnicity (McGuire et al., 1978; Turner, 1987) and group identification (Branscombe et al., 1999; Kaiser \& Wilkins, 2010; Tajfel \& Turner, 1986).

\subsection{Moderation Effect of Racial/Ethnic Identity}

In addition to the search for the main effects of perceived discrimination on self-esteem, scholars have long investigated whether racial/ethnic identity acts as an exacerbating or protective factor in the face of prejudice (Allport, 1954; Crocker et al., 1998; Major \& O’Brien, 2005; Tajfel \& Turner, 1986). Does racial/ethnic identity moderate the link between perceived discrimination and self-esteem among Asian-Americans (Model 3, path $\mathrm{c}$ in Fig. 1)? Again, the research with Asian-Americans is relatively limited and equivocal. On one hand, strong identification with one's racial/ethnic group has been associated with increased vulnerability to prejudice among Asian college students (Operario \& Fiske, 2001; Yoo \& Lee, 2009) and older Asian adults (Yip et al., 2008). On the other hand, racial/ethnic identity and ethnic pride (i.e., positive feelings toward one's group membership) have been shown to buffer the negative psychological impact of perceived discrimination among Korean-Americans (Lee, 2005), Filipino-Americans (Mossakowski, 2003), and middle-aged US-born Asian adults (Yip et al., 2008). Again, given the mixed evidence in the literature, we did not offer a prediction regarding the moderating effect of racial/ethnic identity.

\section{Method}

\subsection{Participant Characteristics}

Participants ( $\mathrm{N}=83$ ) were self-identified Asian-American undergraduate students at the University of California, Berkeley who participated for credit in a psychology course (Note 1). The students (65 were women) ranged in age from 18 to $37(M=20.2, S D=2.6)$. The participants' fathers' educational attainment served as an approximate indicator of socioeconomic status: $32 \%$ (high school graduate or less), $31 \%$ (college graduate), and $37 \%$ (advanced degree). Fifty-one percent of the sample was foreign-born (mean age of immigration: $M=9.0$, $S D=6.2)$. On average, the participants had spent $78.5 \%$ of their lives $(S D=28.9 \%)$ residing in the United States. Among those who were foreign-born, the median number of years spent living in the US was 11.5 years.

\subsection{Measures}

\subsubsection{Perceived Racial/Ethnic Disadvantage}

Perceptions of disadvantage were measured with the 7-item Racial/Ethnic Group Disadvantage Scale (Spencer-Rodgers, Gilbert, \& Peng, 2013). Sample items include: "My racial/ethnic group is treated unfairly by other racial/ethnic groups," "My racial/ethnic group has fewer political resources than other racial/ethnic groups," and "Historically, my racial/ethnic group has been discriminated against by other racial/ethnic groups." The items were rated on a 7-point scale, ranging from 1 (not at all) to 7 (very much). Cronbach's alpha was .76.

\subsubsection{Racial/Ethnic Identity}

Racial/ethnic identity (Spencer-Rodgers \& Collins, 2006) (Note 2) was assessed with 4 items: "I identify with members of my racial/ethnic group," "I feel emotionally attached to other members of my racial/ethnic group," "I feel a common bond with other members of my racial/ethnic group," and "I feel separate from other members of my racial/ethnic group" (reverse-scored). The items were rated on a 7-point scale, ranging from 1 (not at all) to 7 (very much). Cronbach's alpha was .77.

\subsubsection{Racial/Ethnic Salience}

As an indicator of racial/ethnic salience (Masuoka, 2006), we examined the number of ethnic identities (e.g., Japanese, Japanese American) and pan-ethnic identities (e.g., Asian, Asian American) that participants listed on an open-ended measure of the self-concept, the Twenty Statements Test (TST; Kuhn \& McPartland, 1954). The TST included the following standard instructions: "There are twenty numbered blanks on the page below. Please 
write twenty answers to the simple question, 'Who am I?' Answer as if you were giving the answers to yourself, not to anyone else. Work fairly quickly."

\subsubsection{Proportions of Ethnic and Pan-Ethnic Identities}

Two research assistants, blind to hypotheses and working independently, coded the TST responses for the number of ethnic and pan-ethnic identities participants listed. The intercoder agreement was high (Kappa: .84 and. 91). Proportions were computed by dividing the number of ethnic (and pan-ethnic) identities listed by the total number of responses.

\subsubsection{Weighted Ethnic and Pan-Ethnic Identities}

We also examined whether participants in the disadvantage-prime condition were more likely to list an ethnic identity at the beginning versus the end of the TST, as an additional measure of salience (Watkins, Yau, Dahlin, $\&$ Wondimu, 1997). We weighted each response according to its position on the TST (i.e., $1^{\text {st }}$ line $=20$ points, $20^{\text {th }}$ line $=1$ point). Thus, if a participant wrote "Chinese" on line 1 , she obtained a score of 20 . If another participant wrote "Japanese" on line 1 and "Japanese American" on line 15, he obtained a score of 25 (computed as $20+5=25$ ). The same procedures were used for the pan-ethnic identities.

\subsubsection{Self-Esteem}

Self-esteem was assessed with the 10-item Rosenberg Global Self-Esteem Scale (Rosenberg, 1979). The items were rated on a 7-point scale, ranging from 1 (not at all) to 7 (very much). Cronbach's alpha was .91.

\subsection{Research Design}

The study employed a between-participants design, with participants randomly assigned to a control or experimental condition.

\subsection{Procedures and Experimental Manipulation}

We used a disadvantage manipulation that has been used successfully in prior research (Branscombe, 1998). Participants were brought into the lab in small groups (3-6). They were provided with a brief oral and written introduction to the study and a consent form. To reduce suspicion and potential psychological reactivity, the study was described as being about "self-awareness and learning" and whether thinking about one's personal background influences one's motivation to comprehend written information. Participants were randomly assigned to 1 of 2 conditions. Individuals in the disadvantage-prime condition $(\mathrm{N}=38)$ were provided with the following instructions (adapted from Branscombe, 1998):

"We would like you to reflect, in writing, on an experience in your life. Specifically, we would like you to think about and consider the ways that you have been disadvantaged because of your race/ethnicity. Think about a specific memorable experience or situation. Take a moment to think about the experience. Now, please briefly describe the experience."

The instructions were followed by 38 blank lines (1.5 pages). Participants indicated how old they were when the experience occurred. Rather than writing about the ways in which they had been advantaged due to their group membership (Branscombe, 1998), participants in the control condition $(\mathrm{N}=45)$ proceeded immediately to the dependent measures. The Twenty Statements Test and self-esteem measure were completed first and demographic items last. The order of presentation of the remaining measures was counter-balanced. Participants were thoroughly and sensitively debriefed.

\section{Results}

\subsection{Control Variables}

In all analyses, we tested for effects of gender, nativity status ( $0=$ foreign-born, $1=$ US-born $)$, and immigrant status (i.e., percentage of life spent living in the US = [length of US residence/age] x 100), and either controlled for these variables or reported the main effects and interactions. Socioeconomic status, current age, and age at which the racist experience occurred were not related to any of the study variables, and hence, were not considered further.

\subsection{Manipulation Check}

Three participants who reported never having experienced racial/ethnic disadvantage and two participants who did not follow the instructions were excluded from the analyses, thus resulting in a usable sample of $\mathrm{N}=83$. The remaining experimental participants wrote a minimum of 2 paragraphs describing an experience with racial/ethnic disadvantage. An analysis of covariance (ANCOVA) indicated that experimental participants 
scored higher on perceived racial/ethnic disadvantage $(M=4.15, S D=.87)$ than did control participants $(M=$ $3.84, S D=.81), F(1,79)=4.08, p=.042, \eta_{p}{ }^{2}=.05$. (Note 3)

\subsection{Qualitative Analyses: Types of Experiences}

Two research assistants categorized the responses according to type of experience (e.g., social exclusion, being ridiculed, etc.). The intercoder agreement Kappa was .89. Table 1 presents the frequency of occurrence of each type of experience and the median reported age of occurrence.

\subsection{Experimental Effects of Perceiving Racial/Ethnic Disadvantage}

We tested paths a and $b$ (illustrated in Fig. 1) by conducting a multivariate analysis of covariance (MANCOVA). Specifically, a MANCOVA was conducted on the study variables (listed in Table 2), using experimental condition, nativity status, and gender as the factors, and immigrant status as a covariate (Note 4). There were no main effects of nativity status or gender, or interactions involving these variables. The main effects of experimental condition (i.e., mean comparisons, $F, p$, and $\eta_{p}{ }^{2}$ values) are presented in Table 2.

Table 1. Type of disadvantage, frequency, and median age of occurrence

\begin{tabular}{lcc}
\hline Type of Disadvantage & Frequency (\% of Responses) & Median Age of Occurrence \\
\hline $\begin{array}{l}\text { Social exclusion (e.g., feeling left out or } \\
\text { alienated from European-American or }\end{array}$ & $23 \%$ & 14 \\
$\begin{array}{l}\text { Latino peers, the community, etc.) } \\
\text { Being ridiculed (e.g., name calling, } \\
\text { mimicking speech, etc.) }\end{array}$ & $18 \%$ & 11 \\
$\begin{array}{l}\text { Incident involving a clerk or official (e.g., } \\
\text { in a store, airport, post office, etc.) }\end{array}$ & $12 \%$ & 21 \\
$\begin{array}{l}\text { Disadvantage due to linguistic or cultural } \\
\text { barriers }\end{array}$ & $12 \%$ & 16 \\
$\begin{array}{l}\text { Incident involving a professional (teacher, } \\
\text { doctor, etc.) }\end{array}$ & $9 \%$ & 17 \\
$\begin{array}{l}\text { Discrimination in sports (e.g., not being } \\
\text { selected for a team) }\end{array}$ & $9 \%$ & 14 \\
$\begin{array}{l}\text { Feeling stereotyped or like one has failed } \\
\text { to live up to the model minority (e.g., } \\
\text { being expected to be very smart, good at } \\
\text { math, etc.) }\end{array}$ & $6 \%$ & 16 \\
$\begin{array}{l}\text { Disadvantage due to competition with } \\
\text { other Asians (e.g. } \\
\text { applying for college admission, } \\
\text { scholarships, etc.) } \\
\text { Other }\end{array}$ & $6 \%$ & \\
\hline
\end{tabular}

Note. Frequency $=$ (number of responses in each category $\div$ total number of responses).

As expected, Asian-Americans in the disadvantage-prime condition listed a greater proportion of ethnic identities (e.g., Chinese) on the open-ended TST, and they listed them earlier on the measure, indicating that their ethnic group membership was more salient or central to the self-concept. Contrary to prediction, however, they listed fewer pan-ethnic identities (e.g., Asian) and listed them significantly later on the TST. 
Table 2. Mean comparisons by experimental condition

\begin{tabular}{lllllll}
\hline & $\begin{array}{l}\text { Control Group } \\
\text { Mean }(S D)\end{array}$ & & $\begin{array}{l}\text { Exp. Group } \\
\text { Mean }(S D)\end{array}$ & $F$ & $p$ & $\eta_{p}{ }^{2}$ \\
\hline Racial/ethnic identity & $4.78(1.14)$ & $=$ & $4.91(1.04)$ & .85 & .18 & .01 \\
Racial/ethnic salience & & & & & & \\
$\quad$ Prop. ethnic identities & $.028(.03)$ & $<$ & $.049(.04)$ & 8.04 & .003 & .10 \\
Weighted ethnic identities & $9.64(11.24)$ & $<$ & $14.66(14.00)$ & 4.38 & .020 & .06 \\
Prop. pan-ethnic identities & $.017(.02)$ & $>$ & $.012(.02)$ & 3.27 & .038 & .04 \\
Weighted pan-ethnic identities & $5.22(7.68)$ & $>$ & $3.16(6.61)$ & 4.00 & .025 & .05 \\
\hline
\end{tabular}

Note. Degrees of freedom $=74$, one-tailed hypothesis tests.

There was no effect of experimental condition on self-esteem: Asian-Americans in the experimental group ( $M=$ $5.08, S D=1.11)$ and control group $(M=4.87, S D=1.05)$ did not differ, $F(1,74)=.49, p=.49, \eta_{p}{ }^{2}=.01$. The null hypothesis cannot be confirmed, and null effects must be interpreted with caution (Fisher, 1966). Nonetheless, this finding provides support for the buffering hypothesis and theoretical models of self-protection and resilience.

\subsection{Moderation Analyses}

\subsubsection{Experimental Data}

Moderation analyses (Model 3, path c in Fig. 1) were conducted following Aiken and West (1991). All continuous variables were mean-centered. We conducted a hierarchical multiple regression analysis as follows: demographic control variables (gender, nativity status, and immigrant status) were entered as covariates (Note 5) at Step 1, and the main effects of experimental condition $(0=$ control, $1=$ disadvantage-prime $)$ and racial/ethnic identity were entered at Step 2. Lastly, we entered the two-way interaction term (experimental condition $\mathrm{x}$ racial/ethnic identity) at Step 3. The interaction was sizable $(\beta=.42)$, but not significant $\left(p=.44, \Delta R^{2}=.01\right)$ (Note 6).

\subsubsection{Correlational Data}

We conducted a second moderation analysis using the manipulation check (continuous, perceived racial/ethnic disadvantage) as the predictor variable, rather than experimental condition (dichotomous). It is important to note that this analysis, although higher-powered, is correlational rather than experimental in nature.

We conducted the hierarchical multiple regression analysis as follows: demographic control variables (gender, nativity status, and immigrant status) were entered as covariates at Step 1 (Note 5), and the main effects of perceived disadvantage and racial/ethnic identity were entered at Step 2. At Step 2, neither perceived disadvantage $(\beta=-.09, p=.44)$ nor racial/ethnic identity $(\beta=.12, p=.29)$ significantly predicted self-esteem. The two-way interaction term (perceived disadvantage $\mathrm{x}$ racial/ethnic identity) was entered at Step 3 . The change in $R$-squared $\left(\Delta R^{2}=.064, p=.022\right)$ and the interaction were significant $(\beta=.26, p=.022)$. The interaction is shown in Figure 2.

We conducted simple slopes analyses for participants who scored one standard deviation above and below the mean on racial/ethnic identity. Perceived disadvantage was not significantly related to self-esteem among Asian-Americans who were relatively high in racial/ethnic identity, $\beta=.19, p=.25$. Conversely, perceived disadvantage was negatively related to self-esteem among Asian-Americans who were relatively low in racial/ethnic identity, $\beta=-.37, p=.028$. These results, albeit correlational, provide support for the buffering hypothesis.

\section{Discussion}

This study is the first to manipulate perceived racially-based disadvantage among Asian-Americans and examine its effect on self-esteem. As indicated in Table 1, the Asian-American college students reported experiencing various forms of racial/ethnic disadvantage. The most common experience ( $23 \%$ of responses) that students wrote about occurred during adolescence and involved feeling alienated or isolated from European-American, and in some instances, Latino peers. The second most common incident (18\% of responses) took place during childhood and involved being ridiculed (e.g., name calling, mimicking speech, etc.). Many of the students' 
accounts described incidents of relatively blatant prejudice perpetrated by retail clerks and airport officials (12\% of responses), as well as professionals such as teachers and doctors ( $9 \%$ of responses).

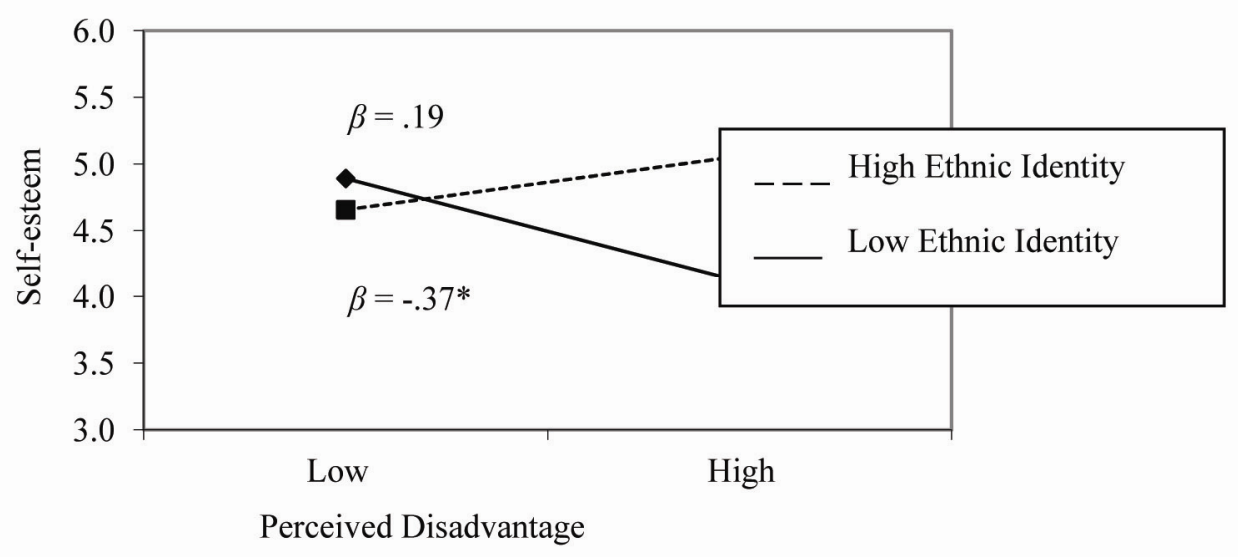

Figure 2. The effect of perceived racially-based disadvantage on self-esteem, as a function of racial/ethnic identity (plotted one standard deviation above and below the mean)

Note. ${ }^{*} p=.028$

\subsection{Experimental Effects of Perceiving Racial/Ethnic Disadvantage}

\subsubsection{Racial/Ethnic Identity and Salience}

Interestingly, on the Twenty Statements Test, the Asian-American students emphasized their specific ethnic identities (e.g., as Korean), but psychologically detached from their pan-ethnic Asian identity. The qualitative analyses showed that many of the students' experiences involved being stereotyped or treated unfairly on the basis of their identity as Asian. This may explain why the experimental participants distanced themselves somewhat from Asian labels (i.e., they listed fewer pan-ethnic identities and listed them later on the TST than did control participants; see Table 2), suggesting they psychologically disengaged from this broader pan-ethnic category. Simultaneously, they emphasized their specific ethnic identities (e.g., as Chinese), indicating these social identities were more salient or central to the self-concept. Another possible explanation for these findings is that one's ethnic group membership, relative to one's pan-ethnic group membership, provides an optimal level of distinctiveness in the face of discrimination threat (i.e., Optimal Distinctiveness Theory, Brewer \& Roccas, 2001).

\subsubsection{Self-Esteem}

Importantly, we found that recalling and describing actual, personal experiences with racial/ethnic disadvantage did not lead to lower self-esteem. Null findings must always be interpreted with caution (Fisher, 1966). Nonetheless, this result is consistent with much of the experimental research with other racial/ethnic minority groups in the United States, such as African-Americans and Latinos, and with theoretical models of self-protection and resilience (for reviews, see Crocker et al., 1998; Major \& O'Brien, 2005).

Notably, our experimental results differ from the bulk of the existing correlational research with Asian-Americans that has found that perceived discrimination is correlated with lower self-esteem (e.g., Gee at al., 2009; Lee \& Ahn, 2011). The vast majority of published studies using Asian-American samples have employed a correlational design, whereas we used an experimental manipulation. Correlational studies examine relatively stable, chronic beliefs that one's group is a target of prejudice and inequitable outcomes in society (i.e., trait-level perceptions). It would be reasonable to expect that Asian-Americans who chronically perceive that their racial/ethnic group is pervasively devalued and disadvantaged in society would be vulnerable to low self-esteem. In this study, we activated a specific memory of racially-based disadvantage among experimental participants (i.e., state-level perceptions) and found that priming perceptions of disadvantage had no appreciable effect on state self-esteem. In sum, we found no evidence to support a causal link between perceived discrimination and self-esteem among Asian-Americans (perceived discrimination $\rightarrow$ self-esteem). 
The classic perspective in the social stigma literature is that racial/ethnic minorities will internalize the prejudicial views of the majority group, and that perceiving discrimination will inevitably lead to low self-esteem and psychological well-being among stigmatized group members (for a review, see Crocker et al., 1998; Major \& Obrien, 2005). The classic perspective overlooks, however, the multitude of factors that contribute to psychological resilience among Asian-Americans, including personality variables (e.g., dispositional optimism), social and cultural factors (e.g., family resources and social support), group identification, and so on (Crocker et al., 1998; Major \& O'Brien, 2005), an extensive discussion of which is beyond the scope of this brief report. Our results suggest that Asian-Americans, like many other racial/ethnic minorities and stigmatized individuals (e.g., homosexuals, the disabled, etc.), are resilient and resistant to the deleterious effects of perceiving discrimination (Crocker et al., 1998; Major \& O'Brien, 2005), at least when recalling past incidents of racial/ethnic disadvantage.

\subsection{Correlational Moderation Effect of Racial/Ethnic Identity}

On an exploratory basis, we tested whether racial/ethnic identity moderated the association between perceived disadvantage and self-esteem. It is important to note that because we used perceived disadvantage (the manipulation check) and measured (not manipulated) racial/ethnic identity as the predictors in this regression analysis, the moderation analyses are correlational rather than experimental in nature. The findings, shown in Figure 2, provide support for the buffering hypothesis: Perceived racial/ethnic disadvantage was unrelated to self-esteem among Asian-Americans who felt highly connected with their group, whereas perceived disadvantage was significantly related to lower self-esteem among Asian-Americans who felt less identified with their group. According to Yoo and Lee (2009), Asian-Americans with a strong sense of racial/ethnic identity may be better able to cope with repeated instances of prejudice by highlighting positive dimensions of their group, whereas people with a weak sense of racial/ethnic identity may lack coping resources (e.g., "clarity, knowledge, and pride of their ethnic group," p. 72). Experimental laboratory studies that manipulate racial/ethnic identity (e.g., by priming valued aspects of one's ethnic group membership) are needed to determine whether racial/ethnic identity has a buffering or exacerbating effect, and to provide causal evidence of its moderating influence.

Our findings differ from those of Yoo and Lee (2009) who found that perceiving discrimination had a negative effect on situational affect among Asian-Americans. A number of factors could explain the discrepancy in our findings, including differences in the measures used, experimental procedures, and participant samples (e.g., a Midwestern vs. West Coast university). Our study focused on self-esteem as the outcome variable rather than current emotions. We employed a manipulation with greater ecological validity, by having Asian-Americans describe an actual personal experience with racial/ethnic disadvantage, rather than imagine a fictitious discriminatory situation. Our study was limited, however, in that the disadvantage manipulation was memory-based and subject to recall biases. Experimental studies that manipulate perceptions of discrimination in real-time by exposing Asian-Americans to analogues of discriminatory events in the laboratory (e.g., a prejudiced experimenter or confederate) are needed. In light of the current findings, the existing literature may have understated the resilience of Asian Americans, and more research is needed on this important topic.

\section{Acknowledgments}

This research was supported by the Cher Wang and Wenchi Chen Foundation and National Institute of Mental Health grant MH072680.

\section{References}

Aiken, L. S., \& West, S. G. (1991). Multiple regression: Testing and interpreting interactions. Newbury Park, London: Sage.

Allport, G. (1954). The nature of prejudice. Cambridge, MA: Addison-Wesley.

Alvarez, A., \& Kimura, E. (2001). Asian-Americans and racial identity: Dealing with racism and snowballs. Journal of Mental Health Counseling, 23(3), 192-206.

Asnaani, A., \& Hofmann, S. (2012). Perception of racial discrimination and psychopathology across three U.S. ethnic minority groups. Cultural Diversity and Ethnic Minority Psychology, 18(1), 74-81. http://dx.doi.org/10.1037/a0025432

Barry, D. T., \& Grilo, C. M. (2003). Cultural, self-esteem, and demographic correlates of perception of personal and group discrimination among East Asian immigrants. American Journal of Orthopsychiatry, 73, 223-229. http://dx.doi.org/10.1037/0002-9432.73.2.223 
Branscombe, N. (1998). Thinking about one's gender group's privileges or disadvantages: Consequences for well-being in women and men. British Journal of Social Psychology, 37, 167-184. http://dx.doi.org/10.1111/j.2044-8309.1998.tb01163.x

Branscombe, N. R., Schmitt, M. T., \& Harvey, R. D. (1999). Perceiving pervasive discrimination among African Americans: Implications for group identification and well-being. Journal of Personality and Social Psychology, 77, 135-149. http://dx.doi.org/10.1037/0022-3514.77.1.135

Brewer, M. B., \& Roccas, S. (2001). Individual values, social identity, and optimal distinctiveness. In C. Sedikides, \& M. B. Brewer (Eds.), Individual self, relational self, collective self (pp. 219-237). New York: Psychology Press.

Chen, H.-J., Mallinckrodt, B., \& Mobley, M. (2002). Attachment patterns of East Asian international students and sources of perceived social support as moderators of the impact of U.S. racism and cultural distress. Asian Journal of Counseling, 9, 27-48.

Chou, T., Asnaani, A., \& Hofmann, S. (2012). Perception of racial discrimination and psychopathology across three U.S. ethnic minority groups. Cultural Diversity and Ethnic Minority Psychology, 18(1), 74-81. http://dx.doi.org/10.1037/a0025432

Crocker, J., \& Major, B. (1989) Social stigma and self-esteem: The self-protective properties of stigma. Psychological Review, 96, 608-630. http://dx.doi.org/10.1037/0033-295x.96.4.608

Downey, G., \& Feldman, S. (1996). Implications of rejection sensitivity for intimate relationships. Journal of Personality and Social Psychology, 70, 1327-1343. http://dx.doi.org/10.1037/0033-2909.117.3.497

Gee, G. C., Ro, A., Shariff-Marco, S., \& Chae, D. (2009). Racial discrimination and health among Asian-Americans: Evidence, assessment, and directions for future research. Epidemiologic Reviews, 31, 130-151.

Gee, G. C., Spencer, M. S., Chen, J., Yip, T., \& Takeuchi, D. T. (2007). The association between self-reported racial discrimination and 12-month DSM-IV mental disorders among Asian Americans nationwide. Social Science \& Medicine, 64(10), 1984-1996. http://dx.doi.org/10.1016/j.socscimed.2007.02.013

Greene, M., Way, N., \& Pahl, K. (2006). Trajectories of perceived adult and peer discrimination among Black, Latino, and Asian American adolescents: Patterns and psychological correlates. Developmental Psychology, 42(2), 218-238. http://dx.doi.org/10.1037/0012-1649.42.2.218

Festinger, L. (1954). A theory of social comparison processes. Human Relations, 7, 71-82.

Fisher, R. A. (1966). The design of experiments. Hafner: Edinburgh.

Hwang, W.-C., \& Goto, S. (2008). The impact of perceived racial discrimination on the mental health of Asian American and Latino college students. Asian American Journal of Psychology, 1, 15-28. http://dx.doi.org/10.1037/1948-1985.S.1.15

Juang, L., \& Alvarez, A. (2010). Discrimination and adjustment among Chinese American adolescents: Family conflict and family cohesion as vulnerability and protective factors. American Journal of Public Health, 100(12), 2403-2409. http://dx.doi.org/10.2105/AJPH.2009.185959

Kaiser, C. R., \& Wilkins, C. (2010). Group identification and prejudice: Theoretical and empirical advances and implications. Journal of Social Issues, 66, 461-476. http://dx.doi.org/10.1111/j.1540-4560.2010.01656.x

Kuhn, M. H., \& McPartland, T. S. (1954). An empirical investigation of self-attitudes. American Sociological Review, 19, 68-76. http://dx.doi.org/10.2307/2088175

Kuo, W. H. (1995). Coping with racial discrimination: The case of Asian-Americans. Ethnic and Racial Studies, 18(1), 109-127.

Lee, R. M. (2003). Do ethnic identity and other-group orientation protect against discrimination for Asian-Americans? Journal of Counseling Psychology, 50, 133-141. http://dx.doi.org/10.1037/0022-0167.50.2.133

Lee, R. M. (2005). Resilience against discrimination: Ethnic identity and other-group orientation as protective factors for Korean Americans. Journal of Counseling Psychology, 52, 36-44. http://dx.doi.org/10.1037/0022-0167.52.1.36

Lee, D. L., \& Ahn, S. (2011). Racial discrimination and Asian mental health: A meta-analysis. The counseling psychologist, 39(3), 463-489. http://dx.doi.org/10.1177/0011000010381791. 
Major, B., Kaiser, C. R., \& McCoy, S. K. (2003). It's not my fault: when and why attributions to prejudice protect self-esteem. Personality and Social Psychology Bulletin, 29, 772-781. http://dx.doi.org/10.1177/0146167203029006009

Major, B., \& O’Brien, L. T. (2005). The social psychology of stigma. Annual Review of Psychology, 56, $393-421$.

Mak, A. S., \& Nesdale, D. (2001). Migrant distress: The role of perceived racial discrimination and coping resources. Journal of Applied Social Psychology, 31, 2632-2647. http://dx.doi.org/10.1111/j.1559-1816.2001.tb00194.x

Masuoka, N. (2006). Together they become one: Examining the predictors of panethnic group consciousness among Asian Americans and Latinos. Social Science Quarterly, 87(5), 993-1011. http://dx.doi.org/10.1111/j.1540-6237.2006.00412.x

McGuire, W. J., McGuire, C. V., Child, P., \& Fujioka, T. (1978). Salience of ethnicity in the spontaneous self-concept as a function of one's ethnic distinctiveness in the social environment. Journal of Personality \& Social Psychology, 36, 511-520. http://dx.doi.org/10.1037/0022-3514.36.5.511

Mead, G. H. (1934). Mind, self and society. Chicago: University of Chicago Press.

Mendoza-Denton, R., Downey, G., Purdie, V. J., Davis, A., \& Pietzak, J. (2002). Sensitivity tostatus-based rejection: Implications for African American students' college experience. Journal of Personality and Social Psychology, 83, 896-918.

Mossakowski, K. (2003). Coping with perceived discrimination: Does ethnic identity protect mental health? Journal of Health and Social Behavior, 44, 318-331. http://dx.doi.org/10.2307/1519782

Noh, S., Beiser, M., Kaspar, V., Hou, F., \& Rummens, J. (1999). Perceived racial discrimination, depression, and coping: A study of Southeast Asian refugees in Canada. Journal of Health and Social Behavior, 40, 193-207. http://dx.doi.org/10.2307/2676348

Noh, S., \& Kaspar, V. (2003). Perceived discrimination and depression: Moderating effects of coping, acculturation, and ethnic support. American Journal of Public Health, 93, 232-238. http://dx.doi.org/10.2105/AJPH.93.2.232

Operario, D., \& Fiske, S. T. (2001). Ethnic identity moderates perceptions of prejudice: Judgments of personal versus group discrimination and subtle versus blatant bias. Personality and Social Psychology Bulletin, 27(5), 550-561. http://dx.doi.org/10.1177/0146167201275004

Phinney, J. (1992). The Multigroup Ethnic Identity Measure: A new scale for use with adolescents and young adults from diverse groups. Journal of Adolescent Research, 7, 156-176.

Rosenberg, M. (1979). Conceiving the self. New York: Basic Books.

Son, D., \& Shelton, J. N. (2011). Stigma consciousness among Asian Americans: Intrapersonal consequences for daily intergroup interactions. Asian American Journal of Psychology, 2(1), 51-60. http://dx.doi.org/10.1037/a0022651

Spencer-Rodgers, J., \& Collins, N. L. (2006). Risk and resilience: Dual effects of perceptions of group disadvantage among Latinos. Journal of Experimental Social Psychology, 42, 729-737. http://dx.doi.org/10.1016/j.jesp.2005.10.009

Spencer-Rodgers, J., Gilbert, M., \& Peng, K. (2013). The Racial/Ethnic Group Disadvantage Scale: A scale for use with multiple groups in diverse geographical contexts. International Journal of Psychological Studies, 5(2), 39-51. http://dx.doi.org/10.5539/ijps.v5n2p32

Spencer-Rodgers, J., \& Peng, K. (2013). Priming culture among Asian-Americans (Unpublished raw data).

Tajfel, H., \& Turner, J. C. (1986). The social identity theory of intergroup behavior. In W. Austin, \& S. Worchel (Eds.), The social psychology of intergroup relations (pp. 7-24). Monterey: Brooks/Cole.

Turner, J. C. (1987). Rediscovering the social group: A self-categorization theory. New York: Blackwell.

Watkins, D., Yau, J., Dahlin, B., \& Wondimu, H. (1997). The Twenty Statements Test: Some measurement issues. Journal of Cross-Cultural Psychology, 28, 626-633. http://dx.doi.org/10.1177/0022022197285007

Yeh, C. J., Carter, R. T., \& Pieterse, A. L. (2004). Cultural values and racial identity attitudes among Asian American students: An exploratory investigation. Counseling and Values, 48, 82-95. http://dx.doi.org/10.1002/j.2161-007X.2004.tb00235.x 
Yip, T. (2005). Sources of situational variation in ethnic identity and psychological well-being: A palm pilot study of Chinese American students. Personality and Social Psychology Bulletin, 31(12), 1603-1616. http://dx.doi.org/10.1177/0146167205277094

Yip, T., Gee, G., \& Takeuchi, D. (2008). Racial discrimination and psychological distress: The impact of ethnic identity and age among immigrant and United States-born Asian adults. Developmental Psychology, 44, 787-800. http://dx.doi.org/10.1037/0012-1649.44.3.787

Yoo, H. C., \& Lee, R. M. (2005). Ethnic identity and approach-type coping as moderators of the racial discrimination/well-being relation in Asian-Americans. Journal of Counseling Psychology, 52, 497-506. http://dx.doi.org/10.1037/0022-0167.52.4.497

Yoo, H. C., \& Lee, R. M. (2009). Does ethnic identity buffer or exacerbate the effects of frequent racial discrimination on situational well-being of Asian-Americans? Asian American Journal of Psychology, $S$, 70-87. http://dx.doi.org/10.1037/1948-1985.S.1.70

\section{Notes}

Note 1 . We did not collect ethnicity data. Typically, the demographic characteristics of Asian-Americans in the research participant pool are as follows: $42 \%$ Chinese, 21\% Korean, 9\% Filipino, $8 \%$ Southeast Asian, $6 \%$ Japanese, and $11 \%$ Other Asian (3\% unreported).

Note 2. Due to time constraints, we sought to administer a brief (4-item) measure of racial/ethnic identity (Spencer-Rodgers \& Collins, 2006). This brief measure is highly correlated $(r[121]=.65, p<.001)$ with the longer Multigroup Ethnic Identity Measure (Phinney, 1992) among Asian-Americans (Spencer-Rodgers \& Peng, 2013).

Note 3. Perceived racial/ethnic disadvantage tended to be related to immigrant status, $r=.20, p=.067$, and gender $(0=$ male, $1=$ female $), r=.22, p=.051$, but no other demographic variable. Therefore, we controlled for immigrant status and gender in this analysis.

Note 4 . The weighted pan-ethnic identity variable was related to immigrant status, $r=.24, p<.05$, such that pan-ethnic identity was stronger the longer participants had lived in the United States. Therefore, immigrant status was included as a covariate in this analysis.

Note 5 . The moderator (racial/ethnic identity) was marginally related to nativity status $(0=$ foreign-born, $1=$ US-born), $r=-.21, p=.057$, but no other demographic variable. Self-esteem was not related to any demographic variable. Because nativity status was marginally correlated with racial/ethnic identity, and gender and immigrant status were marginally correlated with perceived disadvantage (see footnote 3 ), these three demographic variables were included as covariates in the regression analysis.

Note 6 . The relationship between perceived racial/ethnic disadvantage and self-esteem was not moderated by racial/ethnic salience (i.e., the ethnic and pan-ethnic identity variables).

\section{Copyrights}

Copyright for this article is retained by the author(s), with first publication rights granted to the journal.

This is an open-access article distributed under the terms and conditions of the Creative Commons Attribution license (http://creativecommons.org/licenses/by/3.0/). 